\title{
Twenty-First Century Medicine: The Fall of Occam
}

Ben J. Wilson MD

\section{About the Author}

At the time of this writing, Ben Wilson was a 4th-year internal medicine resident at the University of Alberta, in Edmonton, Alberta. Correspondence may be directed to Ben.wilson@albertahealthservices.ca.

\section{Summary}

Medicine has evolved a great deal over the past hundred years, and the automatic and subconscious application of shortcuts increases the risk of oversimplification and inaccuracy. In this article, the author presents a case to illustrate this point.

\section{Résumé}

La médecine a considérablement évolué dans le dernier siècle, et les raccourcis empruntés machinalement de façon subconsciente s'accompagnent d'un risque de simplification excessive et d'inexactitude. Dans son article, l'auteur présente un cas illustrant son propos.

A familiar story: while heading out of the emergency department after a day of admissions, an emergency doctor pulls me over. "Hey, are you on for medicine?"

"I am just heading home," I say tiredly. "What's the story? I'll hand it over."

"I've got this 85-year-old guy with worsening fatigue and some confusion. He is hypercalcemic." While he is filling in the story, my eyes slip over his shoulder to the computer screen where the man's laboratory values are displayed. Calcium $3.34 \mathrm{mmol} / \mathrm{L}$. Albumin $35 \mathrm{~g} / \mathrm{L}$. My eyes then find the CBC and begin their familiar descent down the patient's biochemical profile. Amidst all of the normal, black-boxed values, several red boxes glare conspicuously back at me: hemoglobin $100 \mathrm{~g} / \mathrm{L}$ and creatinine $199 \mu \mathrm{mol} / \mathrm{L}$. The plot thickens. As a differential begins to form in my mind, I reign my eyes back in and direct a more deliberate search. Is his anemia macrocytic, I wonder, as my eyes charge back up the screen to register the mean corpuscular volume? A crimson $107 \mathrm{fL}$ greets my thirsty gaze.

"Oh, man," I said, "this guy could have multiple myeloma. Has he ever had a protein electrophoresis?" The emergency physician scrolls back; a brief mouse click catapulting us past countless columns and boxes - boxes whose dispassionate numerical contents lay coldly disconnected from their sanguineous origins. His cursor ultimately lands on a serum protein electrophoresis (SPEP) from about 1 month back: his light chains were monoclonal and markedly elevated. "Oh jeez," I exclaim, my growing excitement getting the best of my practised equanimity, "this guy does have multiple myeloma!" The emergency physician is suitably impressed. As I trudge off to the consultant's room to page my attending, my initial excitement evolves into a strange sense of confident satisfaction.

Later that night, I was again struck by the uniqueness of this gentleman's case and the strong emotions that it evoked. After some thought, I came to realize that it was the simplicity of the clinical story, and the remarkable sense of certainty that followed, that evoked a deep sense of wonder and exhilaration.

The unification of these disparate biochemical findings had happened automatically. I had stumbled upon a well-known philosophical principle: Occam's razor. The eponymous razor, named after the birthplace of its originator, the friar, William of Occam, ${ }^{1}$ states that the simplest single explanation for a problem is usually the correct one. ${ }^{2}$ This general principle was reportedly first applied to medicine and clinical reasoning by the renowned William Osler. ${ }^{2}$ The razor, widely accepted as a powerful diagnostic heuristic in 20th century medicine, is still touted as worthwhile in contemporary clinical practice.

It was at this point that I faltered (again). If Occam's razor was so useful, accurate, and able to unify the disparate complaints of our modern patients, why was its application so alien to me? Why was it not at the forefront of my diagnostic armamentarium?

The answer lies in the complicated landscape of 21st century medicine. Our current patient demographic suffers from an epidemic of co-morbidity, polypharmacy, 
immunocompromise, and ever-advancing age. Moreover, diagnostic and therapeutic practices have evolved substantially since Osler's time. In his day, at the turn of the 20th century, infectious disease predominated. ${ }^{2}$ The myriad manifestations of contagion, syphilis par excellence, were amenable to Occam's lumping principle. The ready availability of post-Oslerian therapeutics - antimicrobial and otherwise - have dramatically changed the spectrum of disease: chronic diseases have long surpassed their infectious counterparts. Our patients now live longer, have more co-morbidities, take more medications, and undergo a far more dizzying array of diagnostic tests.

If this is the case, why does the razor continue to be touted as useful and relevant? Surely, the realities of modern medicine are better suited to more contemporary wisdom - perhaps that of Dr. John Bamber Hickam (1914-1970). Hickam, the originator of the eponymous dictum, graduated from Harvard Medical School in $1940 .{ }^{1}$ In a sage rebuttal to Occam, he stated that a patient can have as many diagnoses as he damn well pleases. ${ }^{1}$ Compared to the attractive, though diminishingly useful razor, this axiom resonates far more clearly with my experience.

Several days later, and with these thoughts in mind, I ran into the staff internist whom I had signed over to previously. "Hey, how is that guy with the hypercalcemia? Multiple myeloma, right?"

"Well, that's what it looked like at first, but no," he said. I was puzzled. "The patient was essentially a textbook case. He was eating six Ultra Strength TUMS per day - that's almost $2.5 \mathrm{~g}$ of elemental calcium. Far too much for anyone, let alone a guy with his kidneys. I stopped the TUMS and his calcium normalized."

I was startled. Exogenous intake was the cause of his hypercalcemia? What did he mean by "his kidneys"? The sparks from the wheels grinding clumsily in my head must have been obvious, as he continued, amused, "He ended up having chronic kidney disease and long-standing myelodysplasia." That explained the elevated creatinine and the macrocytic anemia. But what about the light chains? Already beginning to reel from my diagnostic hubris, I questioned him no further, stammered my thanks for the follow-up, and retreated into the isolated safety of the consultant's room.

Once there, I immediately headed for a computer, sequentially logging into the patient's electronic medical record (EMR) and then, furtively, Uptodate. Once in the EMR, I quickly scrolled back, past all of those digital columns. This time around, however, my eyes lingered a little longer on their contents. I had a newfound appreciation of their value: the late fruit of a failing marrow. Ultimately arriving at the SPEP row, the kappa and lambda light chains, monoclonal and significantly elevated, sat tauntingly in their red cubicle. I was then struck by another unfortunate fact: I realized that I did not know how to interpret these abnormalities. Trigger the second wave of confidence-crushing ignorance. Before having to find the Uptodate search bar and enter "light chains," my eyes fell upon an explanation at the bottom of the screen. It stated that his particular kappa-lambda ratio lay "within the range that is consistent with kidney failure." This was the final touch: medical reality had once again definitively triumphed over Occam's lump. The conveniently packaged clinical tetrad of myeloma had been dismembered into four constituent and largely unrelated parts.

Ignorance and humility are my constant companions on this journey toward clinical competence. On such a daunting path, the simplicity of heuristics appears especially attractive. However, the automatic and subconscious application of these shortcuts risks oversimplification and inaccuracy. Medicine has evolved a great deal over the past hundred years. We must scrutinize the accuracy of historic ideas with the same rigour that we use to validate current hypotheses. My close shave with Occam's razor has taught me respect for the dictum of Hickam.

\section{Acknowledgement}

The author thanks Dr. Hector Baillie for his insightful editing and inspiration.

\section{References}

1. Maloney WJ. Occam's razor and Hickam's dictum: the transformation of a theoretical discussion into a modern and revolutionary tool in oral diagnostics. WebmedCentral 2011;2(5):WMC001914.

2. Michelson J. Critique if (im)pure reason: evidence-based medicine and common sense. J Eval Clin Pract 2004;10(2):157-61. 